\title{
Establishing a simulation centre in an Indian medical college - the St. John's experience
}

\author{
Shankar, N. ${ }^{1}$, Lagoo, J. ${ }^{2}$, Stephen, J. ${ }^{3}$, Nithyanandam, S. ${ }^{4}$, Lewin, S. ${ }^{5}$
}

\begin{abstract}
As part of the new competency-based curriculum, it has now become mandatory for all medical colleges in India to set up simulation centres for training undergraduate medical students. This article describes the establishment of a simulation centre at St. John's Medical College in India. The important considerations that enabled the success of this process included having a clear vision and mission, identifying and deploying resources effectively, having a transparent, well-defined leadership and administrative structure, conducting timely faculty development programs and the deliberate incorporation of simulation training into the curriculum. The major challenges encountered included the difficulty in involving all faculty due to considerations of time and the development of a viable selfsustaining financial model. Incorporating digital solutions to meet the challenges of tracking student learning as part of the $\mathrm{CBC}$, decentralization of simulation training at the departmental level and establishing the second phase of the centre for speciality and super-specialty training are potential areas that need to be addressed in the future. It is hoped that these experiences will provide some insight to other medical colleges in India and countries with similar contexts as they establish their simulation centres.
\end{abstract}

Keywords: simulation centre, competency-based curriculum, medical college, India

\section{Introduction}

A competency-based curriculum (CBC) for undergraduate medical education in India was introduced in 2019 (Medical Council of India, psychomotor skills by students (Medical Council of India, 2019). A simulation centre is an2019). The curriculum emphasizes the acquisition of the relevant cognitive, affective and important requirement to facilitate the acquisition of these skills (Medical Council of India, 2019). It has now become mandatory for all medical colleges in India to set up simulation centres. The basic requirements and guidelines

${ }^{1}$ Department of Anatomy and Medical Education

${ }^{2}$ Department of Anaesthesiology and Medical Education

${ }^{3}$ Department of Dermatology and Medical Education ${ }^{4}$ Department of Ophthalmology and Medical Education

${ }^{5}$ Department of Paediatrics and Medical Education

St. John's Medical College, Bangalore

Corresponding author: Prof. Nachiket Shankar nachiket.s@stjohns.in for setting up simulation centres have been formulated by the regulatory body for medical education (Medical Council of India, 2019). St. John's Medical College is a premier institution in Bangalore, India which is well known for its excellence in medical education. The institution strives to produce technically competent medical graduates who are compassionate and ethical. In its endeavour to continue this proud tradition amidst rapid societal and technological changes, the institution set up a simulation centre in 2018. Though guidelines for the creation of simulation centres exist, they cater more to developed countries (Lateef, Yin, \& Suppiah, 2019). As a large majority of medical colleges in India are in the process of establishing simulation centres, it is hoped that our experience will provide valuable insights in this regard. A few key issues will be discussed including the vision and mission, resources required, leadership and administrative structure, faculty development, curriculum design, challenges faced and future plans.

DOI: http://doi.org/10.4038/seajme.v15i2.327

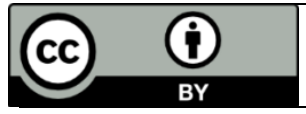

(C) SEAJME. This is an Open Access article distributed under the terms of the Creative Commons Attribution License (http://creativecommons.org/licenses/by/4.0/), which permits unrestricted use, distribution, and reproduction in any medium, provided the original author and source are credited 


\section{Vision and mission}

St. John's Medical College celebrated its golden jubilee in 2013. One of the dreams of the alumni was the setting up of a world class simulation centre. This dream came to fruition in 2018. This successful outcome was the result of many months of planning and effort. The initial plans were put in place by a committee headed by two senior professors from the institution who were experts in the field of medical education. The committee first identified the essential clinical skills that were required to be performed by a basic medical graduate. This list of skills was narrowed down to around 30 skills that could be effectively learned and practiced in the simulation centre. Postgraduate training was also factored into the plans with the identification of suitable highfidelity adult and neonatal simulators. This was the envisaged first phase of the simulation centre. Plans for second phase were also created by the committee. This included the identification of advanced trainers for broad and super-specialties.

\section{Resources}

The construction of the centre was made possible by generous financial contributions by alumni and well-wishers. The location of the centre was an important consideration which was decided based on the convenience of access and proximity to the office of the department of medical education which took charge of its administration. Identification of potential vendors for the procurement of mannequins for the first phase was considered once the needs analysis was performed. After consideration of many factors, the management decided to partner with Laerdal, a reputed simulation company with a significant global presence.

The next stage was the actual implementation of the plans. In the latter half of 2017, the head of the department of medical education was appointed as the head of a team to facilitate this process. Two coordinators, one from the department of anaesthesiology and the other from the department of anatomy were appointed as coordinators of the simulation centre. A series of meetings were conducted with representatives from Laerdal for planning the layout of the simulation centre and the purchase of mannequins. Mention must be made of the leadership and support provided by the institutional management at this critical juncture. The heads of the project office and information technology team also played key roles in implementing the plans. The centre now has more than one hundred mannequins that cater to the requirements of undergraduate medical students, postgraduate students and faculty. The skills that can be practiced include relatively simple ones such as the administration of an intramuscular injection, to complex team-based skills needed for managing critically ill patients. The most advanced of these simulators are SimMan 3G and Newborn Anne. These hi-fidelity simulators can be programmed to simulate a variety of scenarios that would need to be managed by teams in the casualty, operation theatre and intensive care units. Figure 1: The administrative structure of the simulation centre. A) For the day-to-day running; B) For training programs

Soon after the inauguration of the centre, the coordinator from the department of anaesthesiology was placed in-charge of highfidelity simulation training, while the coordinator from the department of anatomy took charge of skills training for undergraduate students. A core committee was created to carry out the training programs that were planned. This committee consisted of faculty members from the departments of general medicine, general surgery, obstetrics and gynaecology, paediatrics, otorhinolaryngology, anaesthesiology, emergency medicine, critical care medicine, paediatric intensive care and neonatology. A key factor in the growth of the centre was the appointment of the technical coordinator to oversee the day-to-day running of the centre. She is a trained nurse whose experience in an ICU setting has proved invaluable. An expansion in the activities of the centre necessitated the appointment of an assistant technical coordinator.

\section{Faculty development}

Faculty development was initially conducted for the coordinators and core committee. Sensitization sessions for the other faculty members were concurrently arranged. The high-fidelity training required multiple sessions which were planned in a phased manner. The coordinators attended more advanced training 
at workshops organized as part of medical simulation conferences. Once the core committee members were trained, they took on the responsibility of training colleagues from their respective departments. As the expertise within the institution continued to develop, workshops were organized for faculty from other medical colleges as well. More advanced training in high fidelity simulation for a few select faculty who have the intention of becoming trainers of trainers continues till date.

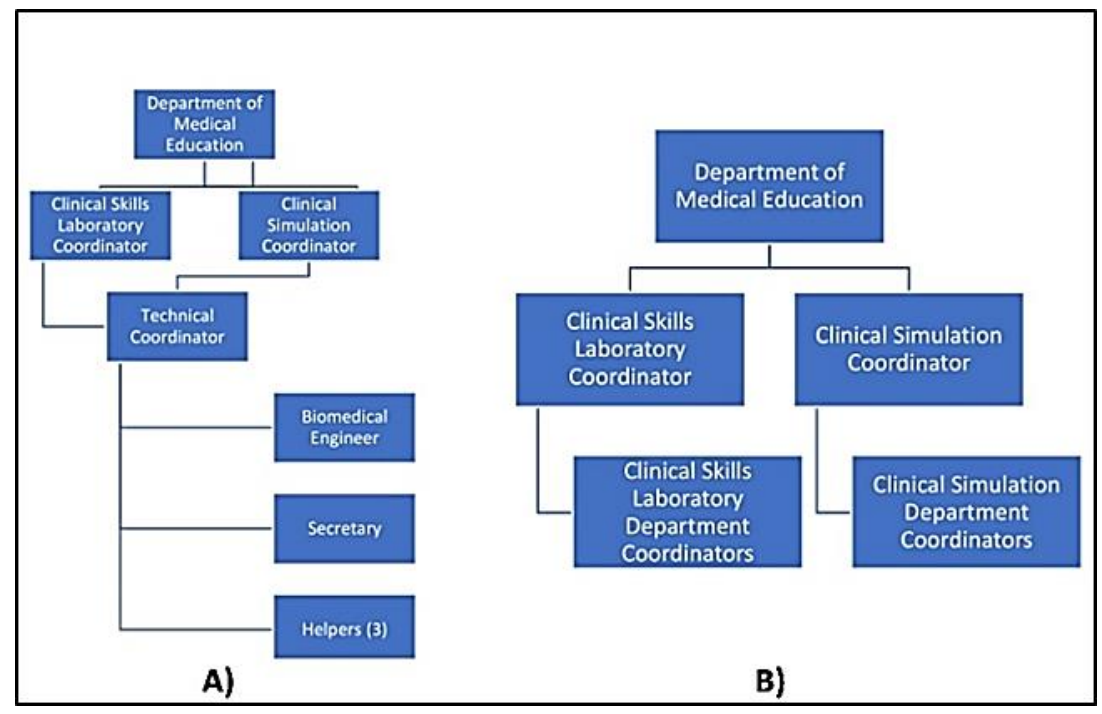

Figure 1: The administrative structure of the simulation centre. A) For the day-to-day running; B) for training programs

\section{Curriculum design}

In the initial stages there was a conscious decision to focus on undergraduate skills training. The departments involved in this process were internal medicine, general surgery, obstetrics and gynaecology, paediatrics, otorhinolaryngology, ophthalmology and anaesthesiology. Considerable care was taken to ensure that skills training was incorporated in the curriculum for the students right from the second till the final year of their course. This was formalized after taking into consideration existing teaching schedules. The remaining time slots from Monday to Thursday were set aside for postgraduate training. The weekends were earmarked for faculty training workshops. The departments involved in undergraduate skills training then undertook the task of developing session plans and checklists. The session plan also included the instruments, equipment and instructional material required for the session. This enabled the technical coordinator to make suitable arrangements for each session. Some of this material has now been incorporated into a logbook which will help students and faculty to track learning progress.

Postgraduate training using high-fidelity mannequins was initiated by the departments of anaesthesiology, general medicine, obstetrics and gynaecology, paediatric intensive care, and neonatology. These departments have now incorporated simulation sessions into their postgraduate training schedules. The sessions take place in the afternoons and evenings after the completion of routine clinical work in the hospital. Basic and advanced life support workshops are conducted by the department of emergency medicine on a regular basis during the weekends.

\section{Challenges}

An important consideration for the sustainability of simulation training is faculty involvement. The additional demands placed on the time of faculty for simulation training can be difficult to manage with all the responsibilities that medical college faculty must fulfil. This issue has been addressed to a certain extent with the implementation of the $\mathrm{CBC}$ which mandates the 
incorporation of simulation training into the regular curriculum. The running of a simulation centre involves considerable recurring expenditure. This expenditure involves salaries of staff, running costs including those of utilities, annual maintenance costs, replacement costs of mannequin parts and the purchase of equipment. Medical colleges need to think of how these expenses can be recovered. The options that could be explored include the conduction of regular workshops and the collection of an annual utilization fee from students who use the simulation centre.

\section{The future}

The CBC is a paradigm shift from the traditional undergraduate medical curriculum. The adaptation of simulation training to meet the requirements of the $\mathrm{CBC}$ is an important consideration for all medical colleges. This would include the development of mechanisms to track the progress of students in the acquisition of skills in the simulation centre. It becomes imperative to incorporate digital solutions for this purpose given the amount of documentation that would be required. While in the initial stages it is convenient for simulation training to occur at a dedicated centre, decentralization of simulation training at the departmental level would be more sustainable. Hence individual departments would need gear up to meet this challenge. The implementation of second phase of the simulation centre for specialty and super-specialty training is a longterm goal. This would involve replicating the processes followed for first phase. Since the costs involved for advanced simulation trainers is considerable, developing a self-sustaining financial model is of paramount importance.

\section{References}

Lateef, F., Yin, S., \& Suppiah, M. (2019) The 2019 WACEM expert document on the framework for setting up a simulation centre. Journal of Emergencies, Trauma and Shock, 12, 4, pp. 232-242.

Medical Council of India. Regulations on Graduate Medical Education (Amendment) (2019). Available from: https://www.nmc.org.in/ActivitiWebClient/open/g etDocument?path=/Documents/Public/Portal/Ga zette/GME-06.11.2019.pdf

Medical Council of India. Skills training module (including guidelines for skills lab) for undergraduate medical education (2019). Available from: https://www.nmc.org.in/MCIRest/open/getDocu ment?path=/Documents/Public/Portal/LatestNe ws/Skill\%20!Module 23.12.2019\%20(1).pdf 